\title{
РАЗМЫШЛЕНИЯ О ДОКУМЕНТАЛЬНОМ И ХУДОЖЕСТВЕННОМ НАЧАЛЕ В ФОТОГРАФИИ
}

\begin{abstract}
Аннотация. С середины ХІХ века в жизни европейского общества произошли значительные социально-культурные перемены, которые существенно изменили представление современного человека об искусстве. В статье рассматривается природа фотографического образа, как особого способа познания окружающего мира. В данной работе автор анализирует различные подходы $к$ содержанию феномена фотоснимка. С одной стороны фотография является новым способом отношения к объективной реальности, через субъективное суждением человека о предмете, а с другой стороны - это возможность приспосабливаться и выживать, сохранять и получать знания о мире. Выступая в различных ролях, фотография имеет возможность концентрировать в себе достижения, как науки, так и искусства, выступать объектом или субъектом в зависимости от целей фотографирования.
\end{abstract}

Ключевъе слова: философия, фотография, культура, общество, искусство, изображение, документальность, художественность, потребность, информация.

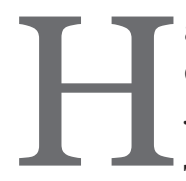
а протяжении всей истории человечества, люди постоянно изобретали различные приспособления (орудия труда - Г.Н.) необходимые им для выполнения общественных и личных целей в процессе жизнедеятельности. В философской антропологии считается, что орудие труда позволило создать совершенно новые отношения с природой, «открыло возможности разнообразных видов деятельности, ухода от узкой специализации» ${ }^{1}$, а использование первых орудий труда способствовало вызреванию социальных связей. Каждому типу общества соответствует свой собственный психологический, экономический, культурный уровень интеракции. Со временем, в каждой новой эпохе эти инструменты постоянно видоизменялись, совершенствовались, появлялись новые в зависимости от потребностей общества. XIX столетие обозначило себя в европейской культуре как эпоха научно-технического прогресса, способного полностью изменить отношения между обществом и внешним, материальным миром.

Задача закрепления изображения на поверхности прошла свое развитие от применения угля до использования сложных химических эле-

\footnotetext{
${ }^{1}$ Ильин В.В., Машенцев А.В. Философия в схемах и комментариях: учебное пособие. СПб.: Питер, 2005. С. 73.
}

ментов. Использование палок, камней, кистей, резцов, карандашей, станков соответствовало творческим требованиям прошлого времени, но для дальнейшего совершенствования копировального процесса требовалось создание сложного технического инструмента, способного точно запечатлеть реальный мир. В середине XIX в. научному сообществу было впервые представлено новое техническое изобретение - фотография. Достигнув определенного научного знания в обществе, появился фотоаппарат, способный с максимальной точностью воспроизвести окружающую реальность. Возможность спонтанно воспроизводить силуэты на двумерной поверхности под воздействием солнца позволила достичь принципиально новой стадии копировального процесса. Появилась возможность «фотогенического рисования, посредством которого природные предметы рисуют себя сами, без помощи карандаша художника ${ }^{2}$. В настоящее время фотография представляет документальное свидетельство исторического времени и одновременно сопровождает частную жизнь человека, фиксируя индивидуальные моменты его существования. В основе фотографического процесса, с одной

\footnotetext{
2 Фризо М. Новая история фотографии. СПб.: Machina; Андрей Наследников, 2008. С. 23.
} 


\section{Философия и культура 1(61) • 2013}

стороны лежит акт создания - фотоаппарат, а с другой стороны продукт этого процесса - изображение. Таким образом, в зависимости от опорной точки анализа, фотография занимает серединное положением между наукой и искусством.

С момента появления фотографии, в среде ученых и исследователей искусства возник противоречивый спор, что же представляет собой фотография - искусство или техническое чудо? В каком когнитивном аспекте ее рассматривать? Какова фотография по своей природе: документальная или творческая? С какой точки зрения ее анализировать: классической эстетики, технических наук или новейшего вида искусства?

Исторически сформировались альтернативные мнения по поводу возникновения теории фотографии. Ученые рассматривают две базисные точки зрения на природу изображения: документальную (репортажную) и художественную (картинную).

Проблема репортажной и критика картинной фотографии рассматривалась так же в советский период в работе «О художественной фотографии и о художественности в фотографии» ${ }^{3}$ исследователя М. Кагана. Ученый высказывает точку зрения, согласно которой, если фотография способна точно воспроизводить пространство, то и основная ее задача запечатлевать важные события человеческой жизни, своего рода замена хроники: «фотография становиться зрительной летописью истории, поставщиком визуальной информации» ${ }^{4}$. Фотоаппарат - это инструмент, а для человека техника всегда служила основой для прикладной деятельности.

Основная проблема состоит в том, что для фотоискусства более органичен «репортажный» прием, а для живописи «художественный». Главной же особенностью фотографии является ее документальность, достоверность: «репортажный момент рассматривается как необходимое качество снимка, придающую ему временную подлинность - качество отличающее технику от живописи» ${ }^{5}$. М. Каган в своем теоретическом очерке определяет образ как художественно-документальный. Он рассматривает образ не просто как отношение объектива к объекту,

\footnotetext{
${ }^{3}$ Каган М. О художественной фотографии и о художественности в фотографии // Советское фото. 1968. № 1. С. 26-27.

${ }^{4}$ Морозов С.В. Творческая фотография. М.: Планета, 1989. C. 162.

${ }^{5}$ Каган М. О художественной фотографии и о художественности в фотографии // Советское фото. 1968. № 1. С. 27.
}

а как отношение эмоционально и психологически подвижного фотографа, от которого зависит, будет ли фотография наделена художественным образом или нет.

В статье «Эстетика и художественная фотография» 6 рассматривается проблема теоретического противопоставления «фотографии и искусства». М. Каган приводит следующие противоречия в кругу исследователей по этому поводу: фотография это механическое явление, а искусство не опирается на автоматизированную технику; фотография создает плоскую копию мира, а искусство продукт созидательной деятельности; фотограф зависит от возможностей своей техники, а искусство свободное творчество 7. Он делает вывод, что мы имеем дело с двумя принципиально разными родами фотографии, источником которых является разные корни. В конце статьи, ученый пытается ответить на вопрос: почему существуют эти различия и чем они отличаются друг от друга?

В изобразительном искусстве документальность, которая показывает физическую реальность, тесно связана с социально-духовной выразительностью. В этом проявляется двуликость изображения фотографии. Можно ли считать, что образ является документальным, главной задачей которого является достоверное запечатление предметов? А субъективность изображения, придумывание различных средств, форм и жанров искусства является лишь косвенной задачей искусства?

Похожего мнения придерживается Г.К. Пондопуло ${ }^{8}$. Он обращает внимание на то, что в Советской России эстетический потенциал фотографии связан с развитием военного репортажа, что очень повлияло на формирование фотографического образа, который может быть представлен путем как художественным, так и документальным.

Исходя из общих рассуждений, и чтобы ответить на вышеперечисленные вопросы необходимо рассмотреть непосредственно художественный подход к фотографии. Можно предположить, что когда древний человек впервые нарисовал изображение животного в пещере, то он уже выражает к нему свое субъективное отношение. Если объект

\footnotetext{
${ }^{6}$ Каган М. Эстетика и художественная фотография // Советское фото. 1968. № 2. С. 26.

7 Там же. С. 22.

8 Пондопуло Г.К. Фотография и современность. М.: Искусство, 1982. 174 с. С. 119.
} 


\section{Философия и искусство}

показался опасным, страшным или непобедимым и героическим, то на его изображении обязательно отразятся психические признаки, которые присвоил ему тот или иной индивид. Человеческое мышление является «процессом отражения объективной действительности в представлениях, суждениях, понятиях»9. Это предполагает взаимодействие субъекта и объекта, через изменяющееся отношение субъекта к действительности, посредством этически-нравственного и культурного оценочного суждения. Таким образом, на первое место можно поставить не точность описания, а эмоционально-оценочное суждение об объекте, а для того, чтобы выразить духовное содержание предмета, его необходимо наделить соответствующей формой.

Фотография, как и картина, показывает отражательную природу предметного мира - это делает ее частью изобразительных искусств. Несомненно, можно отметить, что фотоизображение очень активно использует художественные средства выразительности живописи, имитация кисти или карандаша (особенно в ранних периодах развития фотографии). Даже формирование фотографических жанров практически полностью повторяет существующие художественные жанры искусства. «Поэтому и в фотографии человек видит, прежде всего, картину, подсознательно соотнося воспроизведенные на ней реальные объекты по законам красоты» ${ }^{10}$.

Одной из главных отличительных особенностей классических искусств является способность отражать внутреннее состояние человека, выражение человеческих эмоций посредством субъективности, неповторимости мира художника. Долгое время считалось, что фотоизображение может копировать окружающую реальность независимо от человека, даже высказывались мнения, что снимок это единственное творчество, которое получает неоспоримые «преимущества от отсутствия человека» ${ }^{11}$. Но со временем исследователи стали замечать, что «изображаемый объект предстает перед нами не таким, каков он сам по себе $<\ldots>$ а таким, каков он в субъективном преломлении авторского восприятия, переживания,

\footnotetext{
9 Ожегов С.И., Шведов Н.Ю. Толковый словарь. 24-е изд. М.: Оникс, Мир и образование, 2009. 1036 с. С. 560.

${ }_{10}$ Пондопуло Г.К. Фотография и современность. М.: Искусство, 1982. С. 36.

11 Базен А. Онтология фотографического образа // Что такое кино? М.: Искусство, 1972. С. 41.
}

его духовной оценки» ${ }^{12}$. Случайная возможность существования альтернативного мира, бытия, перенесенного на лист бумаги фотографом, средствами смысловой выразительности придает значение предметам и ситуациям внутри изображения, оживляет его. Это означает присутствие активного самосознания фотографа в фотографической работе. Так как не существует двух одинаковых изображений, сделанных разными людьми одного и того же события.

При анализе предметов из реального мира человеческое мышление создает образ, спонтанно возникающий в сознании. Создавая в голове двусмысленные значения, зрителю дается возможность подумать над произведением, с точки зрения эмоционального заряда, заданной информации автора и творческой фантазии зрителя. В каждом своем произведении автор оставляет что-то загадочное, непонятное, в отличие от научного, где все логически обосновано и представлено. Человек, который смотрит на произведение искусства, видит в образе отражение себя и собственной жизни, он становится как бы соучастником творческого процесса.

Таким образом, если любая картина или фотография несет на себе отпечаток субъективности, отражает любые, даже самые мельчайшие духовно-психические особенности, то на первое место выдвигается художественная составляющая изображения.

Чтобы наши рассуждения были полными, необходимо рассмотреть документальную сторону суждений. Окружающий мир, вокруг человека, постоянно наполнен различными зрительными образами и материальными предметами его культурной жизнедеятельности. Первобытный человек заметил, что некоторые вещества или материалы имеют возможность оставлять после себя видимые следы. Когда он хотел воспроизвести изображение чего-либо на стене, теле, одежде, посуде, то использовал краски и др. До изобретения письма, человек передавал сообщения с помощью символов, знаков. Комплексы символов представляют из себя проблемное поле для интерпретации. Фундаментальная для человека способность к творческой и интеллектуальной деятельности позволила, ему постепенно совершенствовался в социально-культурном плане, получать новые и накапливать старые знания.

\footnotetext{
12 Каган М. Эстетика и художественная фотография // Советское фото. 1968. № 3. С. 26.
} 


\section{Философия и культура 1(61) • 2013}

Однако постепенный переход от словесной культуры к визуальной становится ключевым для понимания эволюции миропонимания человека. Это понимание позволило ему изучать способы воспроизведения объектов.

Если придерживаться документальной точки зрения, то вполне можно предположить, что появление двумерного изображения связано у человека с попыткой запечатлеть реальное существо, создать и сохранить своего рода застывшее воспоминание. Такой способ воспроизведения предметов, диких животных, необъяснимых явлений, позволил человеку приспосабливаться и выживать в условиях дикой природы. Подобной точки зрения придерживаются исследователи функционализма, основная идея данного направления состоит в том, что каждая «атомарная клеточка культуры исследуется не в качестве случайного или ненужного (вредного, архаичного) образования (пережитка), а как, выполняющая определенную задачу, функцию в социокультурной общности» ${ }^{13}$. Человек - существо как биологическое, так и социальное, поэтому не маловажное значение в его жизнедеятельности является искусственная среда, именуемая культурой. Человек не только существует, он взаимодействует в различных сферах: природной, духовной, общественной. Разнообразие культурной жизни показывает многообразие человеческого взаимодействия, его адаптации к внешней среде. Культура того или иного народа как правило выражается в материальных предметах быта. Непосредственным выражением человеческой жизни являются материальные предметы культуры, которые сосредотачивают на себе общественное сознание: орудия труда, жилище, искусство, традиция, моральные ценности, все это является внешними атрибутами культуры.

Основатель функционализма, известный культурный антрополог Б. Малиновский считает, что «человек имеет тело с различными органическими потребностями и потому что он живет в среде, которая для него одновременно и лучший друг и опасный враг» ${ }^{14}$. Все, что появляется в человеческой среде так или иначе связано с защитой от опасностей или удовлетворением биологических

\footnotetext{
13 Белик А.А. Культурология. Антропологические теории культур. М.: Российский гос. гуманит. ун-т, 1999. С. 48.

14 Малиновский Б. Научная теория культуры / перевод с англ. И.В. Утехина. М.: ОГИ, 2005. С. 41.
}

потребностей индивида. Удовлетворяя свои потребности, человек преобразует окружающую среду и создает дополнительное окружение, которое и есть культура. Каждый материальный предмет существует только потому, что его существование жизненно необходимо человеку. Если создается новое техническое изобретение, то значит, в его появлении существует социально-биологическая необходимость, которая включается в созданную систему общественного поведения и преобразует ее. «Потенциально все предметы представляют собой запись человеческой активности и могут служить в качестве указателей более широких общественно-культурных процессов, становясь инструментом теоретически углубленной общественной жизни» ${ }^{15}$. Одним из элементов отражения культурной и общественной жизни является искусство фотографии. Фотография, как ни кто другой, способна запечатлеть все составляющие человеческой жизни.

Вся теория функционализма строится на классической структуре потребностей. Функция фотографии находит свое место на уровнях как низкого порядка (потребность в безопасности, выживании), так и уровнях высокого порядка (познавательная потребность, потребность в уважении) одновременно. «Теория потребностей и их возникновения дает нам более определенное функциональное понимание связи между биологическим, физиологическим и культурным детерминизмом» ${ }^{16}$.

Стремление индивида к полной достоверности отражало его необходимость в реализации культурных, политических, экономических, психологических функций. Отталкиваясь от сложности общественной жизнедеятельности, возможно, выделить функции, которые выполняет фотография как феномен человеческой потребности.

В первую очередь, это функция поддержания целостности общества, так как каждый элемент культуры, выполняя специфическую задачу, заполняет пробелы в подвижной социальной системе. Человеческое общество, как и биологическая среда, состоит из множества самоорганизующихся частиц, значение которых не всегда понятно и объяснимо, но в совокупности создающих устойчивую структуру. Если удалить какой-либо компонент структуры, не заменив его равноценным

\footnotetext{
15 Штомпка П. Визуальная социология. М.: Логос, 2007. 168 c. C. 39.

16 Там же. С. 144.
} 


\section{Философия и искусство}

по значению, то вся система может деградировать. Фотография как часть любой культуры занимает особое положение в социально-экономической среде.

Информативность фотографии. Анатомическими подробностями своих картин славились художники различных эпох, одни восхищались красотой здорового, божественного человеческого тела, вторые желали удовлетворить стремление к изучению естественных наук, третьи пытались воспроизвести жизнь во всей своей реальности (Пуссен Н., Лоррен К., Энгр Ж.О.Д., Брюллов К., Рембрандт Д., Рубенс П., Веласкес Д., Караваджо М., Л. да Винчи, Шишкин И., Репин И., Суриков В., Серов В.). Ботанические иллюстрации, пейзажи иностранные государств, картография - вот небольшие примеры насыщенные информацией изображений. Изобразительные поверхности всегда имели свойства носителя и хранителя информации: картины исторических событий использовались в образовательной деятельности, иконы привносили религиозное воспитание в обществе и другое;

Интегративная функция фотографии позволяет индивидам социализироваться, приспособиться к отношениям, которые существует в данном сообществе и их окружающей среде. Фотография показывает взгляд человека и его отношение к объекту. Изображения примитивных сообществ и их образа жизни не вызовут шока или агрессивных эмоций у других людей, при встрече с ними, если они уже видели это на фотографии.

Символическая функция фотографии состоит в многозначности изображаемого объекта. Обладая знаковой составляющей, фотография посредством символов может воспроизводить и передавать конкретные культурные ценности. Образы показывают нам скрытые морально-нравственные отношения между людьми, духовную составляющую общества.

В книге «Культурология. Антропологические теории культур» А.А. Белик выделяет некоторые общие функций культуры, часть которых можно применить к фотографии внешнего характера: нормативно-регулятивная функция культуры, состоящая в поддержании некоего равновесного состояния в общности, содержащая институциональные формы разрешения конфликтов; компенсаторная функция культуры, основное назначение которой - разрядка эмоционального и физического напряжения.
Обращая внимание на представленную точку зрения, можно предполагать, что основополагающей функцией рисунка/изображения является документирование информации с целью выживания и использования ее всеми членами сообщества. Создавая зарисовки охоты, незнакомой местности, соседних поселений, человек приобрел возможность быстро ориентироваться на территории, отличать вредоносное от благоприятного, конкурировать и побеждать.

Мы рассмотрели два основных подхода к значению изображения в фотографии. С одной стороны, она служит для удовлетворения эстетических потребностей, с другой стороны - для удовлетворения биологических потребностей индивида. Две разносторонние и крайне противоречивые точки зрения, каждая из которых пытается отстоять свой подход к пониманию сложного феномена фотографии.

Если утверждать, что фотография является художественным произведением, то главным в фотоснимке становится образ, в котором запечатлены мимолетные чувства, имманентные состояния человеческой души. Способность фотографии передавать невидимые глазу мельчайшие мимические и двигательные реакции, настроение человека, особым образом схватывать атмосферу композиции, при взгляде на которую человек переживает те же ощущения, что и во время съемки. Опираясь на эстетическую составляющую фотографии можно утверждать, что «излишняя» реалистичность фотоснимка является недостатком, дополнительным свойством фотографии. Чтобы привнести в изображение творческую жилку «чрезмерный» реализм необходимо видоизменить методом монтажа.

Если само по себе изображение является документальным, то любая картина или фотография являются фактами документирования чего-либо, будь то реальное событие, воспоминание, психологическое состояние человека. То есть, фотоснимок становится результатом «нашедшей выход» информации. Человек воспринимает предметы субъективно, он наделяет его эмоциями, верованиями, значениями, потому что сами объекты этими характеристиками не обладают. Окружающая действительность становится многозначной благодаря человеческой субъективности, но факт остается фактом в общей для всех реальности. «Человечность» вторична по отношению к объективности мира. 


\section{Философия и культура 1(61) • 2013}

Таким образом, рассматривая картину или скульптуру, мы должны оценивать ее, в первую очередь, с точки зрения поразительной реалистичности предмета, естественной красоты природы как таковой, и уже потом с точки зрения общепризнанной эстетики и собственного вкуса. В своем физическом существовании изображение фотографии дает нам больше вероятностных значений реальности, чем может дать один художник. На основании вышесказанного, можно утверждать, что фотография априори является документальной.

Но, на наш взгляд, можно выделить еще одну обобщающую точку зрения к фотографии. Морозов С.В. однажды написал, что смотрит «на художественную фотографию как на видоизмененную техникой живопись и графику» ${ }^{17}$. Этим высказыванием, автор раскрывает сущность фотографии как нового вида творчества, созданного особым способом модификации классического искусства техническим средством. На основании такого суждения, приведенные выше противоречия и разногласия по поводу сущностного содержания фотографии можно считать абсурдными. Но несмотря на это, фотография преодолевает в себе «расхождение между природой и культурой, искусством и наукой» ${ }^{18}$, она помогает восприятию человека установить связь между материальной действительностью и абстрактной культурой. «Художественный образ в фотоискусстве, в отличие от образа в живописи, образ художественнодокументальный» ${ }^{19}$.

Фотография является принципиально новым уровнем развития в научной и художественной сфере. Соединяя в себе особенности, как технического аппарата, так и возможности художественного выражения, фотография взяла на себя ответственность отказаться от классического понимания искусства и совместить две принципиально разные области знаний в одной плоскости. При этом художественное и документальное направления фотографии можно рассматривать как по отдельности, так и в совокупности, в зависимости от требуемого анализа. Показателен пример ученого-физика Л. ди Бойля, выдвинув-

\footnotetext{
${ }_{17}$ Морозов С.В. Творческая фотография. М.: Планета, 1989. C. 389 .

18 Пондопуло Г.К. Фотография и современность. М.: Искусство, 1982. С. 58.

19 Каган М. Эстетика и художественная фотография // Советское фото. 1968. № 3. С. 26.
}

шего в 1923 году гипотезу об универсальности материи, согласно которой все частицы одновременно обладают двойственными свойствами. Однако, в настоящее время, эта теория, которая говорит нам, что на самом деле частицы не обладают полностью классическим пониманием дуализма, а лишь приближаются к нему. Поэтому используется более корректная формулировка, свободная от классический понятий. Все это говорит, о потребности создавать принципиально новые понятия для сложных явлений, которые являются чем-то другим, не применимым для классического восприятия. Аналогичным образом, и в определенных условиях фотоснимки так же могут проявлять универсальность. Фотография является квинтэссенцией, конечным этапом достижения искусством и наукой полной адекватности изображения, принципиально новым видом деятельности не в классическом понимании изображения.

На основе вышеизложенного материала можно сделать вывод, что, с одной стороны, фотография - это способ выражения нового отношения к реальности, который наполнен эмоционально-оценочным суждением об объекте. С другой стороны, возможность передавать точную визуальную информацию придает фотографии статус ценного предмета для приспособления и выживания, способного сохранять и получать знания. С третьей стороны, документальность не отрицает эстетичность, а эстетичность не исключает документальность, все зависит от итоговой цели фотографирования. Так как фотография является одним из видов визуальных исследований, мы попытались проанализировать ее с новой культурологической точки зрения, показывая разницу между изображением-искусством и изображением-документом, определив последние не просто как предмет истории, а как определенную жизненную потребность общества, посредством фотографии, адаптироваться к внешней среде.

Тем не менее, с нашей точки зрения, объективность фотографии, освобожденной от человеческой субъективности, имеет практически бесконечную коннотативность фотографических объектов, что позволяет создать более широкую научную область для изучения феномена фотографии. 


\section{Философия и искусство}

\section{Список литературъ:}

1. Базен А. Онтология фотографического образа // Что такое кино? М.: Искусство, 1972. С. 40-46.

2. Белик А.А. Культурология. Антропологические теории культур. М.: Российский гос. гуманит. ун-т, 1999. $241 \mathrm{c}$

3. Ильин В.В., Машенцев А.В. Философия в схемах и комментариях: учебное пособие. СПб: Питер, 2005. 304 c.

4. Каган М. О художественной фотографии и о художественности в фотографии // Советское фото. 1968. № 1. C. 26-27.

5. Каган М. Эстетика и художественная фотография // Советское фото. 1968. № 2-8.

6. Малиновский Б. Научная теория культуры. М.: ОГИ, 2005. 184 с.

7. Морозов С.В. Творческая фотография. М.: Планета, 1989. 215 с.

8. Ожегов С.И., Шведов Н.Ю. Толковый словарь. 24-е изд. М.: Оникс, Мир и образование, 2009. 1036 с.

9. Пондопуло Г.К. Фотография и современность. М.: Искусство, 1982. 174 с.

10. Фризо М. Новая история фотографии. СПб: Machina; Андрей Наследников, 2008. 334 с.: илл.

11. Штомпка П. Визуальная социология. М.: Логос, 2007. 168 с.

\section{References (transliteration):}

1. Bazen A. Ontologiya fotograficheskogo obraza // Chto takoe kino? M.: Iskusstvo, 1972. S. 40-46.

2. Belik A.A. Kul'turologiya. Antropologicheskie teorii kul'tur. M.: Rossiyskiy gos. gumanit. un-t, 1999. $241 \mathrm{~s}$.

3. Il'in V.V., Mashentsev A.V. Filosofiya v skhemakh i kommentariyakh: uchebnoe posobie. SPb: Piter, 2005. $304 \mathrm{~s}$.

4. Kagan M. O khudozhestvennoy fotografii i o khudozhestvennosti v fotografii // Sovetskoe foto. 1968. № 1. S. 26-27.

5. Kagan M. Estetika i khudozhestvennaya fotografiya // Sovetskoe foto. 1968. № 2-8.

6. Malinovskiy B. Nauchnaya teoriya kul'tury. M.: OGI, 2005. $184 \mathrm{s.}$

7. Morozov S.V. Tvorcheskaya fotografiya. M.: Planeta, 1989. $215 \mathrm{s.}$

8. Ozhegov S.I., Shvedov N.Yu. Tolkovyy slovar'. 24-e izd. M.: Oniks, Mir i obrazovanie, 2009. 1036 s.

9. Pondopulo G.K. Fotografiya i sovremennost'. M.: Iskusstvo, 1982. 174 s.

10. Frizo M. Novaya istoriya fotografii. SPb: Machina; Andrey Naslednikov, 2008. 334s.: ill.

11. Shtompka P. Vizual'naya sotsiologiya. M.: Logos, 2007. $168 \mathrm{~s}$. 